\title{
Correction to: an automatic water detection approach using Landsat 8 OLI and Google earth engine cloud computing to map lakes and reservoirs in New Zealand
}

\author{
Uyen N. T. Nguyen (Dien T. H. Pham • Thanh Duc Dang
}

Published online: 2 September 2020

(C) Springer Nature Switzerland AG 2020

\section{Correction to: Environ Monit Assess (2019) 191: 235 \\ https://doi.org/10.1007/s10661-019-7355-x}

In the published article: "An automatic water detection approach using Landsat 8 OLI and Google Earth Engine cloud computing to map lakes and reservoirs in New Zealand", the Acknowledgements was published incorrectly and funding statement was missing. The authors apologize for any inconvenience that it may have caused.

The corrected Acknowledgement and missing funding statement are given below.

Acknowledgement This research was conducted during postdoctoral position of the first author, supported by

The online version of the original article can be found at https://doi.org/10.1007/s10661-019-7355-x

U. N. T. Nguyen $(\bowtie)$

Environmental Research Institute, The University of Waikato,

Hamilton, New Zealand

e-mail: uyenn@email.arizona.edu

L. T. H. Pham

HCMC University of Science, Vietnam National University, Ho Chi Minh City, Vietnam

T. D. Dang

Institute for Water and Environment Research, Thuy Loi

University, Ho Chi Minh City, Vietnam the Lake Ecosystem Restoration New Zealand program (LERNZ), funded by the New Zealand Ministry for Business, Employment and Innovation grant number UOWX1503. The first author would like to thank all investigators under this programme and her colleagues for the support and inputs during her postdoc position. Her special gratitude to her formal advisor Dr. David Hamilton and the team leader Dr. Moritz Lehmann for their advice, support, valuable discussion and inputs during her postdoctoral position at the University of Waikato.

Funding This research was conducted during the postdoctoral position funded by the New Zealand Ministry for Business, Employment and Innovation grant number UOWX1503.

Publisher's note Springer Nature remains neutral with regard to jurisdictional claims in published maps and institutional affiliations. 